\title{
Fatos e fake news: conhecimento de estudantes de Enfermagem frente à pandemia da COVID-19
}

\author{
Fact and fake news: knowledge of Nursing student facing the COVID-19 pandemic \\ Hechos e fake news: conocimiento de estudiantes de Enfermeira que enfrentam la pandemia \\ COVID-19
}

Recebido: 03/10/2021 | Revisado: 09/10/2021 | Aceito: 13/10/2021 | Publicado: 16/10/2021

\author{
Aluisio da Silva Oliveira \\ ORCID: https://orcid.org/0000-0002-0636-0686 \\ Universidade Federal do Maranhão, Brasil \\ E-mail: as.oliveira@ufma.br \\ Amanda Jordão Silva de Deus \\ ORCID: https://orcid.org/0000-0001-8952-8108 \\ Universidade Federal do Maranhão, Brasil \\ E-mail:amandajordao87@hotmail.com \\ Eudes Alves Simões Neto \\ ORCID: https://orcid.org/0000-0001-5449-5908 \\ Universidade Federal do Maranhão, Brasil \\ E-mail: eudes.simoes@ufma.br \\ Bruna de Oliveira de Melo \\ ORCID: https://orcid.org/0000-0001-7617-0813 \\ Universidade CEUMA, Brasil \\ E-mail: brunaoliv.96@gmail.com \\ Flávio Augusto Barros Nogueira \\ ORCID: https://orcid.org/0000-0002-9530-7261 \\ Universidade CEUMA, Brasi \\ E-mail: augustofabn@gmail.com \\ Ana Carla Mendes Ahamad Jaber \\ ORCID: https://orcid.org/0000-0003-0198-1544 \\ Universidade Federal do Maranhão, Brasil \\ E-mail: anacarlamendesahamadjaber@yahoo.com.br \\ Larissa dos Reis Ferreira \\ ORCID: https://orcid.org/0000-0001-8766-0156 \\ E-mail: lari.reis.ferreira@gmail.com \\ Universidade CEUMA, Maranhão, Brasil \\ Rayssa de Sousa Silva \\ ORCID: https://orcid.org/0000-0002-4034-6159 \\ Universidade CEUMA, Brasil \\ E-mail: ra.silva2706@gmail.com \\ Eduardo Martins de Sousa \\ ORCID: https://orcid.org/0000-0002-2506-169X \\ Universidade CEUMA, Brasil \\ E-mail: eduardo.martins@ceuma.br \\ Lívia Camara de Carvalho Galvao \\ ORCID: https://orcid.org/0000-0001-9540-649X \\ Universidade CEUMA, Brasil \\ E-mail:livia.camara@ceuma.br
}

\begin{abstract}
Resumo
A pandemia da COVID-19 trouxe mudanças no cotidiano em todo o mundo, o isolamento e o distanciamento social aumentaram a busca por informações em redes sociais e meios de comunicação. As fake news geraram confusão e insegurança. Nesse contexto, cientistas, profissionais e estudantes da saúde desempenham um papel importante no esclarecimento de dúvidas da população. Para avaliar o conhecimento de estudantes do Curso de Enfermagem da Universidade Federal do Maranhão em relação à pandemia da COVID-19, foi aplicado um questionário eletrônico abordando fatos e fake news. Verificamos que 90,8\% afirmaram que as fake news podem ter contribuído para aumentar a transmissão do vírus SARS-COV2. Jornais televisivos, sites de notícias e artigos científicos foram os meios usados, com $81.8 \%, 72.7 \%$ e $68.2 \%$, respectivamente e $40 \%$ usaram redes sociais. Os estudantes consideraram fake news: $86.4 \%$ a hipótese de que o vírus possa ter sido criado em laboratório, $100 \%$ que o vírus possa ser resultante da influência eletromagnética da rede de dados, $95.5 \%$ que o uso de termômetros infravermelhos cause danos cerebrais, $100 \%$ que drogas como a Cloroquina, Ivermectina e Azitromicina possam ser utilizadas tanto para
\end{abstract}


prevenção como para o tratamento e $100 \%$ de que quem já teve COVID-19 não precisa ser vacinado. Como intervenção, foi realizada uma palestra online, identificando os pontos prejudiciais e susceptíveis de divulgações falsas, seguida de questionário pós-intervenção. Constatamos que $100 \%$ dos estudantes responderam ser capazes de diferenciar fake news de informações verdadeiras, evidenciando a importância de fontes confiáveis e a transmissão de orientações verdadeiras à população.

Palavras-chave: Pandemia; COVID-19; Fake news; Fatos.

\begin{abstract}
The COVID-19 pandemic brought changes in daily life, isolation and social distancing increased the search for information in the media and social networks. Fake news generated confusion and insecurity. Health professionals and students play an important role in clarifying the population's doubts. To assess the knowledge of students from the Nursing Course at the Federal University of Maranhão in relation to the COVID-19 pandemic, an electronic questionnaire covering facts and fake news was applied. We found that $90.8 \%$ stated that fake news may have contributed to increase the transmission of the SARS-COV2 virus. Television newspapers, news sites and scientific articles were the media used, with $81.8 \%, 72.7 \%$ and $68.2 \%$, respectively, and $40 \%$ using social media. Students considered fake news: $86.4 \%$ the hypothesis that the virus might have been created in the laboratory, $100 \%$ that the virus might be the result of the electromagnetic influence of the data network, $95.5 \%$ that the use of infrared thermometers causes brain damage, $100 \%$ that drugs such as Chloroquine, Ivermectin and Azithromycin can be used for both prevention and treatment and $100 \%$ that those who have already had COVID-19 do not need to be vaccinated. As an intervention, an online lecture was held, identifying the harmful points and susceptible to false disclosures, followed by a post-intervention questionnaire. We found that $100 \%$ of students responded that they were able to differentiate fake news from true information, highlighting the importance of reliable sources and the transmission of true guidance to the population.
\end{abstract}

Keywords: Pandemic; COVID-19; Fake news; Facts.

\title{
Resumen
}

La pandemia COVID-19 trajo cambios en la vida diaria, el aislamiento y el distanciamiento social aumentaron la búsqueda de información en los medios y redes sociales. Las noticias falsas generaron confusión e inseguridad. Los profesionales de la salud y los estudiantes juegan un papel importante en el esclarecimiento de las dudas de la población. Para evaluar el conocimiento de los estudiantes del Curso de Enfermería de la Universidad Federal de Maranhão en relación a la pandemia COVID-19, se aplicó un cuestionario electrónico que cubría hechos y fake news. Encontramos que el 90,8\% afirmó que las noticias falsas pueden haber contribuido a aumentar la transmisión del virus SARS-COV2. Los medios de comunicación utilizados fueron los periódicos de televisión, los sitios de noticias y los artículos científicos, con $81,8 \%, 72,7 \%$ y $68,2 \%$, respectivamente, y $40 \%$ utilizando las redes sociales. Los estudiantes consideraron noticias falsas: $86,4 \%$ la hipótesis de que el virus podría haber sido creado en el laboratorio, $100 \%$ que el virus podría ser el resultado de la influencia electromagnética de la red de datos, 95,5\% que el uso de termómetros infrarrojos causa daño cerebral, El $100 \%$ que medicamentos como la cloroquina, la ivermectina y la azitromicina pueden usarse tanto para la prevención como para el tratamiento y el 100\% que quienes ya han tenido COVID-19 no necesitan vacunarse. Como intervención se realizó una charla online, identificando los puntos nocivos y susceptibles de falsas revelaciones, seguida de un cuestionario posintervención. Encontramos que el 100\% de los estudiantes respondieron que eran capaces de diferenciar las noticias falsas de la información verdadera, destacando la importancia de las fuentes confiables y la transmisión de una verdadera orientación a la población.

Palabras clave: Pandemia; COVID-19; Noticias falsas; Hechos.

\section{Introdução}

As doenças virais sempre foram alvos de preocupação por serem responsáveis por graves problemas de saúde pública. Nas últimas décadas foram relatadas a Síndrome Respiratória Aguda por Coronavírus (SARS-CoV) em 2002, Influenza por H1N1, Síndrome Respiratória por Coronavírus do Oriente Médio (MERS-CoV), Ebola e o vírus Zika (Majumder \& Minko, 2021).

Em dezembro de 2019, a Organização Mundial de Saúde (OMS) foi notificada por Wuhan, Província de Hubei, China, da existência de casos de pneumonia de etiologia indefinida que, logo no início de janeiro foi identificado como sendo causada por um novo coronavírus, denominado SARS-CoV-2. Posteriormente, a sua doença foi nomeada com COVID-19. O vírus se espalhou de forma exponencial e em 11 de março de 2020 foi declarada oficialmente como uma pandemia (WHO, 2020). 
Os coronavírus pertencem à ordem Nidovirales na família Coronaviridae. As subfamílias Coronavirinae e Torovirinae são divisões da família. A subfamília Coronavirinae é subdividida em quatro gêneros: Alpha, Beta, Gamma e Delta Coronavírus. A análise filogenética revelou que o SARS-CoV-2 está intimamente relacionado com o beta-coronavírus (Fahmi, Kubota e Ito, 2020).

Acredita-se que a transmissão do SARS-CoV-2 ocorra entre pessoas por meio de aerossóis e/ou gotículas expelidas durante espirros ou tosse, que são capazes de infectar alguém que esteja parado em frente a uma pessoa infectada (Jayaweera, Perera, Gunawardana \& Manatunge, 2020). Estudos revelam que o SARS-CoV-2 permaneceria viável no ar por um período de 3 horas ou até mesmo em superfícies por dias, dependendo da quantidade de vírus, aptos a infectar hospedeiros humanos (van Doremalen et al., 2020).

Os sintomas da COVID-19 são observados aproximadamente 5 dias após a incubação e os infectados podem exibir sintomas por até 11 dias, mostrando uma estreita relação com o sistema imunológico e a idade do paciente. Entre os principais sintomas podem ser citados os gastrintestinais, incluindo diarreia, vômito e anorexia, além de infecções do trato respiratório, pneumonia, tosse seca e intensa, sinais de febre e problemas associados à coagulação (Wang et al., 2020).

Em outubro de 2020, já haviam mais de 34,3 milhões de casos confirmados em todo o mundo e mais de 1.000.000 de mortes em 180 países (WHO, 2020; Dong, Du \& Gardner, 2020). No momento da escrita desse texto, 6 de julho de 2021, o Brasil registra 18.769.808 milhões de casos confirmados e 524.417 mortes decorrentes do novo coronavírus (WHO, 2021).

A COVID-19 causou uma interrupção sem precedentes em diversos campos da sociedade, na economia, na educação e no sistema de saúde em todo o mundo. Dessa forma, o distanciamento social foi recomendado como estratégia de controle do fluxo populacional, com redução das atividades comerciais não essenciais, proibição da circulação de pessoas em eventos e transportes públicos, fechamento de escolas e universidades. Autoridades governamentais estabeleceram o uso de máscaras e a higienização das mãos com álcool em gel e a lavagem das mãos com água e sabão como medidas de prevenção. Nesse contexto, o público de forma geral sofreu profundos impactos na saúde emocional e bem-estar (Tian et al., 2020; Galhardi, Freire, Minayo \& Fagundes 2020).

Associado às modificações ocasionadas pela pandemia no convívio social (enfrentadas pelo distanciamento social) e também institucional (adaptação de universidades e escolas ao novo contexto), os meios de comunicação de massa e as redes sociais ganharam ainda mais um papel importante na divulgação de informações ao público. Por outro lado, a desinformação e as fake news (notícias falsas) representam um grande problema, por gerar confusão e insegurança na população (Tagliabue, Galassi \& Mariani, 2020).

Como consequência, a essa crescente disseminação de informações, nem sempre precisas, passamos a vivenciar outro problema bastante sério, relacionado a propagação de notícias falsas relacionadas à COVID-19, originadas principalmente de redes sociais e difundidas pelo aplicativo de mensagens instantâneas WhatsApp. A própria OMS, passou a usar o termo "infodemia", para conceituar a disseminação em massa de notícias falsas e rumores que comprometem a credibilidade das explicações oficiais fundamentadas em respaldo científico. O excesso de fake news coloca em xeque a credibilidade da imprensa, da ciência e de instituições democráticas (Galhardi, Freire, Minayo \& Fagundes 2020; Zaracostas, 2020). A relevância é tamanha que levou a um posicionamento formal de várias entidades internacionais, dentre elas OMS, ONU, UNICEF, UNESCO e UNAIDS. Neste documento, afirmam que infodemia é a tentativa deliberada de disseminar informações erradas com objetivo de minar a resposta da saúde pública e promover agendas alternativas de grupos ou indivíduos. Neste mesmo documento, afirmam que a desinformação pode ser prejudicial à saúde, tanto física quanto mental, à medida que aumenta a estigmatização, leva à não observância das medidas sanitárias, colocando em risco a capacidade dos países em conter a pandemia (WHO, 2020). 
Islam et al. (2020), fizeram um levantamento das informações relacionadas à COVID-19 publicadas nas redes sociais (facebook, twitter, etc) e site de notícias de televisões e jornais, caracterizando em três tipos: rumores (informações não verificadas que podem ser verdadeiras, fabricadas ou totalmente falsas); estigma (informações que geram um processo de descriminação ou desvalorização de um grupo); e teorias conspiratórias (explicações sobre grupos ou pessoas maliciosas que trabalham de forma escondida para fazer o mal). Eles avaliaram mais de 2.300 publicações, e encontraram que $89 \%$ eram rumores, $7.8 \%$ teorias conspiratórias e 3.5\% estigmas. Além disso, $24 \%$ eram informações sobre doença, transmissão e mortalidade, $21 \%$ sobre intervenções de controle, $19 \%$ sobre tratamento e cura e $15 \%$ sobre a causa da doença, incluindo a origem do vírus. A maioria dessas informações estavam em fontes vindas de seis países: Índia, Estados Unidos da América, China, Espanha, Indonésia e Brasil.

Dados mostram que entre as fake news amplamente divulgadas, 65\% delas ensinavam métodos caseiros para prevenir o contágio da COVID-19; $20 \%$ mostravam métodos caseiros para curar a doença; 5.7\% se referiam a golpes bancários; 5\% faziam menção a golpes sobre arrecadações para instituição de pesquisa; e 4.3\% diziam respeito ao uso do novo coronavírus como estratégia política. A pesquisa apontou ainda que, $10.5 \%$ das notícias falsas foram publicadas no Instagram, $15.8 \%$ no Facebook e 73.7\% circularam via WhatsApp (Galhardi, Freire, Minayo \& Fagundes 2020).

Conjuntamente, uma fake news que traz muitas preocupações diz respeito à adesão ao processo de vacinação, onde a desinformação funciona como desincentivo à população, principalmente quando publicada por profissionais de saúde. Entre as principais informações divulgadas, as que associam a vacina a efeitos colaterais são as que causam maior medo à população. No sentido de contrapor essas premissas, as autoridades governamentais têm trabalhado sobre uma abordagem educativa e na informação verdadeira, persuadindo a população dos benefícios de uma vacina.

Os estudos revelam que a televisão, a imprensa eletrônica e sites de notícias são relatados como mais confiáveis do que as redes sociais na obtenção de informações sobre a COVID-19. E que a estratégia mais comum de busca no ambiente digital foi usando palavras-chaves. Informações não confiáveis, notícias falsas e sobrecarga de informações foram as dificuldades mais comuns que os participantes encontraram ao buscar informações sobre a COVID-19 (Skarpa \& Garoufallou, 2021). A exposição à fake news pode resultar em memórias falsas, afetar o conhecimento de indivíduos, a forma como interage com as informações e a capacidade de pensar criticamente, além de colocar em risco a adesão dos cidadãos aos cuidados cientificamente comprovados (Greene \& Murphy, 2020).

Fagundes et al. (2021) mostraram a percepção dos jovens sobre fake news na ciência, evidenciando que há insegurança e dificuldade de identificar o que realmente é verdadeiro e em quem confiar quando se trata de notícias que circulam na internet. Dentre os jovens, os estudantes da área da saúde têm papel importante na divulgação de informações, pois normalmente são os primeiros a terem acesso a textos científicos, aulas e palestras, por outro lado, esses mesmos estudantes estão continuamente conectados às redes sociais como Twitter, Facebook, Instagram, onde são rotineiramente expostos às informações falsas. Assim, nos propomos a analisar o conhecimento de estudantes no que diz respeitos aos fatos e fakes amplamente disseminados durante a pandemia da COVID-19, bem como intervir, esclarecendo a esses alunos informações verdadeiras baseadas em publicações científicas e outras fontes seguras.

A pandemia da COVID-19 trouxe mudanças significativas no cotidiano em todo o mundo, o isolamento e o distanciamento social se fizeram e ainda se fazem presentes na rotina de muitos cidadãos, que aos poucos tentam retornar às suas rotinas. Com o isolamento, as pessoas passaram ainda mais a consumir informações dos diversos meios de comunicação, utilizando a internet e mais especificamente as redes sociais para se informarem. Assim, se torna crescente a preocupação na forma como as pessoas filtram essas informações, se são verdadeiras ou se estão mescladas à notícias falsas (fake news).

Uma gama de informações sobre a biologia do vírus SARS-CoV-2, modos de contágio, medidas de distanciamento e higiene, uso de máscaras, tratamentos e vacinas, precisam chegar até às pessoas de forma correta. Nesse contexto, cientistas, 
profissionais e estudantes da saúde vem desempenhando um papel importantíssimo no cuidado e nos esclarecimentos acerca de dúvidas frequentes da população.

Mas de que maneira essa disseminação de fake news pode influenciar no conhecimento de estudantes da saúde? Será que ao repassar informações a amigos, familiares ou à população em geral usam textos científicos ou se por estarem rotineiramente conectados às redes sociais acabam sendo influenciados e confundidos por fake news?

Dessa forma, esse projeto buscou avaliar o conhecimento de estudantes de enfermagem acerca de diversos assuntos relacionados à pandemia da COVID-19, analisando a capacidade de discernir entre fatos e fake news.

\section{Metodologia}

\subsection{Público alvo e local}

Estudantes do $4^{\circ}$ período do Curso de Enfermagem da Universidade Federal do Maranhão - Campus Pinheiro

\subsection{Coleta e análise das informações}

As informações sobre o conhecimento dos estudantes acerca de fatos e fakes news associados à pandemia da COVID19 foi realizada por meio de questionário eletrônico (APÊNDICE A e B) elaborado usando a plataforma Google forms e aplicado de forma online, onde os alunos responderam questões relacionadas ao Coronavírus, vacinas e da pandemia da COVID-19 (Costa et al., 2020).

\subsection{Execução da proposta de intervenção}

Após a coleta e análise dos dados obtidos por meio do formulário eletrônico os alunos foram convidados a participar de uma palestra via plataforma online onde a equipe executora abordou os pontos mais relevantes identificados como prejudiciais e susceptíveis de causarem confusão acerca dos conhecimentos dos estudantes sobre a pandemia da COVID19. Em seguida foi aplicado um questionário pós-intervenção com a finalidade de avaliar possíveis mudanças no conhecimento dos alunos com a palestra (Ludke \& Andre, 2013; Estrela, 2018).

\section{Resultados e Discussão}

Segundo os dados obtidos por meio do questionário de intervenção com o objetivo de avaliar como fatos e fake news podem interferir no conhecimento de estudantes de Enfermagem da Universidade Federal do Maranhão frente à pandemia da COVID-19 podemos inferir que são estudantes jovens com idade entre 18 e 30 anos, onde $63.6 \%$ se consideram seguros em diferenciar fake news de informações verdadeiras e $90.8 \%$ acreditam que as fake news podem ter contribuído para aumentar a transmissão do vírus causador da COVID-19.

Os dados mostraram que os estudantes utilizam diferentes meios de comunicação para obter informações sobre a COVID-19, entre os mais citados estão os jornais televisivos, sites de notícias e artigos científicos, com 81.8\%, 72.7\% e $68.2 \%$, respectivamente. Este dado é interessante, pois mesmo a população sendo jovem, ainda recorre com muita frequência a jornais televisivos. Destaca-se a baixa frequência de uso de redes sociais como fonte de informação no grupo analisado (máximo de 40\%).

Quanto aos aspectos relacionados à transmissão do vírus SARS-COV-2, 86.4\% dos estudantes afirmaram tratar-se de fake news a hipótese de que o vírus possa ter sido criado em laboratório. Todos (100\%) reconheceram como fake news a informação de que crianças não podem contrair o coronavírus, assim como a COVID-19 possa ser resultante da influência eletromagnética da rede de dados 5G. Ainda nesse aspecto, $72.7 \%$ afirmaram ser fake news a possibilidade de transmissão do vírus por animais domésticos. Estes dados demonstram que a população analisada está munida de informações verídicas com 
relação a estas perguntas, podendo inferir que as suas fontes de informação devem ser confiáveis. Para $54.5 \%$ dos estudantes a informação de que o vírus permanece por mais tempo em superfícies de plástico é verdadeira. Assim como, $68.2 \%$ reconheceram como sendo fake news a necessidade de expor roupas ao sol para que o vírus seja eliminado completamente, pois somente a lavagem com água e sabão não seriam suficientes.

Quantos aos aspectos relacionados às medidas de higiene e proteção é unânime (100\%) entre os estudantes que as máscaras devem ser utilizadas como forma de proteção pessoal e coletiva, que ao serem utilizadas diminuem a chance de contágio e transmissão do vírus. No que se refere ao distanciamento social, $100 \%$ informaram como sendo fake news, quando divulgam que medidas mais rígidas como lockdown (termo em inglês, usado quando as recomendações para de distanciamento social tornam-se obrigatórias) não têm impacto no controle da pandemia. Dado importantíssimo, haja vista a grande quantidade de notícias falsas relacionadas às duas medidas mais importantes no controle da doença.

Os estudantes afirmaram também (95.5\%) tratar-se de fake news a possibilidade de o uso de termômetros infravermelhos causar danos cerebrais. Quando avaliados sobre conhecimentos referentes a tratamentos para a COVID-19, $100 \%$ dos estudantes afirmaram reconhecer como fake news que drogas como a Cloroquina, Ivermectina e Azitromicina possam ser utilizadas tanto para prevenção como para o tratamento da COVID-19, assim como tratamentos alternativos como chá de limão com bicarbonato auxiliam na eliminação do vírus e consequentemente na cura da doença. Mais um dado relevante à medida que infere que as fontes de informação desta população devem ser confiáveis. Por outro lado, 59.1\% acreditam que a maioria das pessoas que adoecem por COVID-19 devem fazer uso de antibiótico para tratar o quadro de pneumonia ocasionado pelo vírus. Este é um dado bastante preocupante, haja vista que menos de 10\% dos casos de COVID-19 possuem infecção bacteriana associada, tornando o uso de antimicrobianos a exceção.

No quesito vacinação, $77.3 \%$ dos estudantes afirmaram não possuir medo ou receios das vacinas, ou seja, mais de $20 \%$ dos entrevistados não se sentem seguros com relação às vacinas. Apesar disso, $100 \%$ reconheceram como sendo fake news a informação de que quem já teve COVID-19 não precisa ser vacinado, assim como, a afirmação de que as vacinas que utilizam a técnica de manipulação com RNA mensageiro são capazes de interferir no DNA humano. Por outro lado, quase metade dos entrevistados (45.5\%) entendem que a presença de trombose prévia seja uma contraindicação para uso da AstraZeneca, e $59.1 \%$ afirmaram ser fake que a vacinação previne em $100 \%$ os casos de óbitos. Estes dois últimos resultados demonstram que as notícias veiculadas a respeito das vacinas possuem muitas inseguranças relacionadas, à medida que não fortalecem as informações verdadeiras. E 95.5\% demonstraram ser conscientes de que a afirmação que o uso de máscara é desnecessário a aqueles que já se vacinaram, trata-se de uma fake news.

\section{Considerações Finais}

Concluímos que após o questionário pós-intervenção que houve mudança em relação a opinião dos alunos em se sentirem confiantes frente a assuntos referentes à pandemia da COVID-19. De um modo geral os estudantes de enfermagem do $4^{\circ}$ período de enfermagem da Universidade Federal do Maranhão apresentaram um bom conhecimento frente aos diversos assuntos abordados. A abordagem foi importante em identificar quais pontos e informações precisaram de intervenção, dessa forma, visou não somente no esclarecimento dessas informações, mas também, alertou aos estudantes a importância que eles têm na transmissão de orientações verdadeiras, baseadas em fontes confiáveis, para que possam assim dar um retorno justo à população.

Este trabalho agrega conhecimento a respeito de como as notificas falsas podem influenciar a população, inclusive os profissionais de saúde. Para que estes dados tenham mais peso, se faz necessário trabalhos com populações maiores e que envolvam estratégias de intervenção que tornem os indivíduos mais "imunes" às fake news. 


\section{Referências}

Costa, G. D. E., Carvalho, J. H. dos S., Zagmignan, A., Pereira, C. D. da S., Castro, Érima J. M., Pessoa, F. S., Macedo, G. H. R. V. de, Monteiro, J. de M., Silva, L. C. N. da, Evangelista, R. D., Lacerda, E. M. da C. B., \& Sousa, E. M. de. (2020). Cough cough: discovering tuberculosis. Research, Society and Development, 9(8), e776986392. https://doi.org/10.33448/rsd-v9i8.6392

Dong, E., Du, H. \& Gardner, L. (2020). An interactive web-based dashboard to track COVID-19 in real time. The Lancet infectious diseases. 20 (5), 533-4.

Estrela, C. (2018). Metodologia Científica: Ciência, Ensino, Pesquisa. Editora Artes Médicas.

Fagundes, V. O., Massarani, L., Castelfranchi, Y., Mendes, I. M., Carvalho, V. B., Malcher, M. A., Miranda, F. C., \& Lopes, S. C. (2021). Jovens e sua percepção sobre fake news na ciência. Boletim do Museu Paraense Emílio Goeldi. Ciências Humanas [online]. 2021 , v. 16, n. 1 e20200027. https://doi.org/10.1590/2178-2547-BGOELDI-2020-0027.

Fahmi, M., Kubota, Y., \& Ito, M. (2020). Nonstructural proteins NS7b and NS8 are likely to be phylogenetically associated with evolution of 2019nCoV. Infection, genetics and evolution: journal of molecular epidemiology and evolutionary genetics in infectious diseases, 81 , 104272. https://doi.org/10.1016/j.meegid.2020.104272.

Galhardi, C. P., Freire, N. P., Minayo, M., \& Fagundes, M. (2020). Fact or Fake? An analysis of disinformation regarding the Covid-19 pandemic in Brazil. Fato ou Fake? Uma análise da desinformação frente à pandemia da Covid-19 no Brasil. Ciencia \& saude coletiva,25(suppl 2), 4201-4210. https://doi.org/10.1590/1413-812320202510.2.28922020

Greene, C. M., \& Murphy, G. (2020). Individual differences in susceptibility to false memories for COVID-19 fake news. Cognitive research: principles and implications, 5(1), 63. https://doi.org/10.1186/s41235-020-00262-1

Islam, M. S., Sarkar, T., Khan, S. H., Mostofa Kamal, A. H., Hasan, S., Kabir, A., Yeasmin, D., Islam, M. A., Amin Chowdhury, K. I., Anwar, K. S., Chughtai, A. A., \& Seale, H. (2020). COVID-19-Related Infodemic and Its Impact on Public Health: A Global Social Media Analysis. The American journal of tropical medicine and hygiene, 103(4), 1621-1629. https://doi.org/10.4269/ajtmh.20-0812

Jayaweera, M., Perera, H., Gunawardana, B., \& Manatunge, J. (2020). Transmission of COVID-19 virus by droplets and aerosols: A critical review on the unresolved dichotomy. Environmental research, 188, 109819. https://doi.org/10.1016/j.envres.2020.109819

Ludke, M. \& Andre, M. E . D. A. (2013). Pesquisas em educação: uma abordagem qualitativa. São Paulo: E.P.U.

Majumder, J., \& Minko, T. (2021). Recent Developments on Therapeutic and Diagnostic Approaches for COVID-19. The AAPS journal, 23(1), 14. https://doi.org/10.1208/s12248-020-00532-2

Olsen, S. J., Chang, H. L., Cheung, T. Y., Tang, A. F., Fisk, T. L., Ooi, S. P., Kuo, H. W., Jiang, D. D., Chen, K. T., Lando, J., Hsu, K. H., Chen, T. J., \& Dowell, S. F. (2003). Transmission of the severe acute respiratory syndrome on aircraft. The New England journal of medicine, 349(25), 2416-2422. https://doi.org/10.1056/NEJMoa031349

Skarpa, P. E., \& Garoufallou, E. (2021). Information seeking behavior and COVID-19 pandemic: A snapshot of young, middle aged and senior individuals in Greece. International journal of medical informatics, 150, 104465. https://doi.org/10.1016/j.ijmedinf.2021.104465

Tagliabue, F., Galassi, L., \& Mariani, P. (2020). The "Pandemic" of Disinformation in COVID-19. SN comprehensive clinical medicine, 1-3. Advance online publication. https://doi.org/10.1007/s42399-020-00439-1

Tian, F., Li, H., Tian, S., Yang, J., Shao, J., \& Tian, C. (2020). Psychological symptoms of ordinary Chinese citizens based on SCL-90 during the level I emergency response to COVID-19. Psychiatry research, 288, 112992. https://doi.org/10.1016/j.psychres.2020.112992

van Doremalen, N., Bushmaker, T., Morris, D. H., Holbrook, M. G., Gamble, A., Williamson, B. N., Tamin, A., Harcourt, J. L., Thornburg, N. J., Gerber, S. I., Lloyd-Smith, J. O., de Wit, E., \& Munster, V. J. (2020). Aerosol and Surface Stability of SARS-CoV-2 as Compared with SARS-CoV-1. The New England journal of medicine, 382(16), 1564-1567. https://doi.org/10.1056/NEJMc2004973

Wang, D., Hu, B., Hu, C., Zhu, F., Liu, X., Zhang, J., Wang, B., Xiang, H., Cheng, Z., Xiong, Y., Zhao, Y., Li, Y., Wang, X., \& Peng, Z. (2020). Clinical Characteristics of 138 Hospitalized Patients With 2019 Novel Coronavirus-Infected Pneumonia in Wuhan, China. JAMA, 323(11), 1061-1069. https://doi.org/10.1001/jama.2020.1585

WHO (2021). Brazil Situation. World Health Organization (WHO). https://covid19.who.int/region/amro/country/br

WHO (2020). Director-General's opening remarks at the media briefing on COVID-19-11 March 2020. World Health Organization (WHO). https://www.who.int/director-general/speeches/detail/who-director-general-s-opening-remarks-at-the-media-briefing-on-covid-19---11-march-2020

WHO (2020). Managing the COVID-19 infodemic: Promoting healthy behaviours and mitigating the harm from misinformation and disinformation. Joint Statement. https://www.who.int/news/item/23-09-2020-managing-the-covid-19-infodemic-promoting-healthy-behaviours-and-mitigating-the-harm-frommisinformation-and-disinformation

Zarocostas J. (2020). How to fight an infodemic. Lancet (London, England), 395(10225), 676. https://doi.org/10.1016/S0140-6736(20)30461-X 


\section{APÊNDICE}

\section{Apêndice A - Questionário pré-Intervenção}

O questionário abaixo é parte integrante de um projeto de Intervenção dos Programas de Pós Graduação em Biologia Microbiana e Programa de Pós Graduação em Ciências da Saúde da Universidade Ceuma e Universidade Federal do Maranhão (UFMA), respectivamente.

A finalidade do projeto é identificar o conhecimento acerca da COVID-19, tendo como foco as Fake News disseminadas ao longo da pandemia, bem como realizar a divulgação correta de informações como mecanismos de transmissão, medidas sanitárias e vacinação, culminando na divulgação de resultados a fim de aumentar o conhecimento e reduzir a propagação de notícias falsas.

Por fim, é de suma importância sua participação, bem como a sinceridade nas respostas, não sendo necessárias consultas na internet, nem a outras fontes para responder ao questionário.

As informações aqui prestadas serão sigilosas e com intuito acadêmico e não serão usadas contra o participante.

\section{QUESTIONÁRIO A}

1. Nome (opcional)

2. Idade

3. Grau de Instrução/Formação

4. Você saberia diferenciar Fake News de informações verdadeiras sobre a COVID-19?
a. ( ) Sim ( ) Não

5. Qual o meio você mais utiliza para obter informações sobre a COVID-19?
a. ( ) Jornais televisivos
b. ( ) Sites
c. ( ) WhatsApp
d. ( ) Instagram
e. ( ) Facebook
f. () Twitter
g. ( ) Artigos científicos
h. ( ) Outros:

6. Você acredita que as Fake News podem ter contribuído para aumentar a transmissão do vírus causador da COVID-1

a. ( ) sim ( ) não

7. Assinale Fato ou Fake News nas alternativas abaixo:

a. O novo coronavírus, SARS-CoV-2, causador da COVID-19, foi criado em laboratório.

$$
\text { i. ( ) Fato ( ) Fake News }
$$

b. As máscaras devem ser utilizadas como forma de proteção pessoal e coletiva. Ao serem utilizadas estaremos diminuindo a chance de contágio e transmissão do vírus.

$$
\text { i. ( ) Fato ( ) Fake News }
$$

c. Drogas como cloroquina, ivermectina e azitromicina podem ser utilizadas tanto para a prevenção quanto para o tratamento da COVID-19
i. ( ) Fato ( ) Fake News

d. Chá de limão com bicarbonato quente auxilia na eliminação viral e consequente cura da COVID-19. i. ( ) Fato ( ) Fake News

e. A lavagem das roupas após o contato com o vírus deve ser feita com a utilização de água, sabão e exposição ao sol, pois somente a utilização de água e sabão não é o bastante para sua eliminação. i. ( ) Fato ( ) Fake News

f. O vírus permanece por mais tempo em superfícies de plástico i. ( ) Fato ( ) Fake News

g. Crianças não podem contrair o Coronavírus. i. ( ) Fato ( ) Fake News

h. A COVID-19 é resultado da influência eletromagnética da rede de dados 5G. 


\section{i. ( ) Fato ( ) Fake News}

i. Quem já teve COVID-19 não precisa ser vacinado.

i. ( ) Fato ( ) Fake News

j. Por ser uma vacina que utiliza RNA mensageiro (Pfizer/BioNTech) é capaz de mexer no DNA humano. i. ( ) Fato ( ) Fake News

k. Animais domésticos podem transmitir o Coronavírus. i. ( ) Fato ( ) Fake News

1. O uso de termômetros infravermelhos causa danos cerebrais i. ( ) Fato ( ) Fake News

m. Pessoas que já tiveram trombose não devem tomar a vacina da AstraZeneca i. ( ) Fato ( ) Fake News

n. As medidas de distanciamento social mais severas (lockdown) não tem impacto no controle da pandemia.

i. ( ) Fato ( ) Fake News

o. Quem está vacinado não precisa utilizar máscara, pois não transmite mais o vírus. i. ( ) Fato ( ) Fake News

p. A maioria das pessoas que adoecem de COVID-19 deve receber antibiótico para tratar pneumonia. i. ( ) Fato ( ) Fake News

q. A vacinação contra a COVID-19 previne em $100 \%$ os casos de óbito. i. ( ) Fato ( ) Fake News

r. Você possui algum medo/receio acerca das vacinas contra COVID-19? i. ( ) Sim ( ) Não Se sim, quais?

\section{Apêndice B - Questionário pós-Intervenção}

O questionário abaixo é parte integrante de um projeto de Intervenção dos Programas de Pós Graduação em Biologia Microbiana e Programa de Pós Graduação em Ciências da Saúde da Universidade Ceuma e Universidade Federal do Maranhão (UFMA), respectivamente.

A finalidade do projeto é identificar o conhecimento acerca da COVID-19, tendo como foco as Fake News disseminadas ao longo da pandemia, bem como realizar a divulgação correta de informações como mecanismos de transmissão, medidas sanitárias e vacinação, culminando na divulgação de resultados a fim de aumentar o conhecimento e reduzir a propagação de notícias falsas.

Por fim, é de suma importância sua participação, bem como a sinceridade nas respostas, não sendo necessárias consultas na internet, nem a outras fontes para responder ao questionário.

As informações aqui prestadas serão sigilosas e com intuito acadêmico e não serão usadas contra o participante.

\section{QUESTIONÁRIO B}

8. Nome (opcional)

9. Idade

10. Grau de Instrução/Formação

11. Você saberia diferenciar Fake News de informações verdadeiras sobre a COVID-19?
a. ( ) Sim ( ) Não

12. Qual o meio você mais utiliza para obter informações sobre a COVID-19?

a. ( ) Jornais televisivos

b. ( ) Sites

c. ( ) WhatsApp

d. ( ) Instagram

e. ( ) Facebook

f. ( ) Twitter 
g. ( ) Artigos científicos

h. ( ) Outros:

13. Você acredita que as Fake News podem ter contribuído para aumentar a transmissão do vírus causador da COVID-1

a. ( ) sim ( ) não

14. Assinale Fato ou Fake News nas alternativas abaixo:

a. O novo coronavírus, SARS-CoV-2, causador da COVID-19, foi criado em laboratório.

$$
\text { i. ( ) Fato ( ) Fake News }
$$

b. As máscaras devem ser utilizadas como forma de proteção pessoal e coletiva. Ao serem utilizadas estaremos diminuindo a chance de contágio e transmissão do vírus.

$$
\text { i. ( ) Fato ( ) Fake News }
$$

c. Drogas como cloroquina, ivermectina e azitromicina podem ser utilizadas tanto para a prevenção quanto para o tratamento da COVID-19
i. ( ) Fato ( ) Fake News

d. Chá de limão com bicarbonato quente auxilia na eliminação viral e consequente cura da COVID-19.

$$
\text { i. ( ) Fato ( ) Fake News }
$$

e. A lavagem das roupas após o contato com o vírus deve ser feita com a utilização de água, sabão e exposição ao sol, pois somente a utilização de água e sabão não é o bastante para sua eliminação.

$$
\text { i. ( ) Fato ( ) Fake News }
$$

f. O vírus permanece por mais tempo em superfícies de plástico
i. ( ) Fato ( ) Fake News

g. Crianças não podem contrair o Coronavírus.

$$
\text { i. ( ) Fato ( ) Fake News }
$$

h. A COVID-19 é resultado da influência eletromagnética da rede de dados 5 G.
i. ( ) Fato ( ) Fake News

i. Quem já teve COVID-19 não precisa ser vacinado.

$$
\text { i. ( ) Fato ( ) Fake News }
$$

j. Por ser uma vacina que utiliza RNA mensageiro (Pfizer/BioNTech) é capaz de mexer no DNA humano.

$$
\text { i. ( ) Fato ( ) Fake News }
$$

k. Animais domésticos podem transmitir o Coronavírus.

$$
\text { i. ( ) Fato ( ) Fake News }
$$

l. O uso de termômetros infravermelhos causa danos cerebrais
i. ( ) Fato ( ) Fake News

m. Pessoas que já tiveram trombose não devem tomar a vacina da AstraZeneca

$$
\text { i. ( ) Fato ( ) Fake News }
$$

n. As medidas de distanciamento social $m$ ais severas (lockdown) não tem impacto no controle da pandemia.

$$
\text { i. ( ) Fato ( ) Fake News }
$$

o. Quem está vacinado não precisa utilizar máscara, pois não transmite mais o vírus.

$$
\text { i. ( ) Fato ( ) Fake News }
$$

p. A maioria das pessoas que adoecem de COVID-19 deve receber antibiótico para tratar pneumonia.

$$
\text { i. ( ) Fato ( ) Fake News }
$$

q. A vacinação contra a COVID-19 previne em $100 \%$ os casos de óbito.

$$
\text { i. ( ) Fato ( ) Fake News }
$$

r. Você continua possuindo algum medo/receio acerca das vacinas contra COVID-19?

$$
\text { i. ( ) Sim ( ) Não Se sim, quais? }
$$

